\title{
TEORÍAS PARA UN CANON DE LA CRÍTICA LITERARIA
}

\author{
José DOMÍNGUEZ CAPARRÓS \\ Universidad Nacional de Educación a Distancia \\ jdominguez@flog.uned.es
}

Resumen: En el artículo se comenta un conjunto de ideas y actitudes que la teoría del siglo XX proporciona a la crítica literaria: inmanentismo de los formalismos; preocupación por el significado en la semiología; interpretación en la hermenéutica. Se propone una lista de diez títulos de teoría.

Abstract: This work comments the ideas borrowed by the literary criticism from the literary theory: the formalists' immanentism; the semiology's interest on the signification; or the attention of the hermeneutics to the interpretation. A list of ten titles of literary theory is given at the end.

Palabras clave: Crítica literaria. Canon. Inmanentismo. Semiología. Hermenéutica.

Key Words: Literary criticism. Canon. Immanentism. Semiology. Hermeneutics. 
Relacionar la crítica literaria con el canon, tal y como se hace en el título, en algún sentido es instalarse en el terreno de lo paradójico, de la antítesis, de la oposición contradictoria entre dos conceptos. En definitiva, el título parece un oxímoron que une sintácticamente dos antónimos: canon y crítica literaria. ¿En qué sentido se oponen canon y crítica literaria? En que uno y otra establecen un trato muy distinto con el tiempo. Si el canon exige un trabajo del tiempo que va salvando como modelo y ejemplo de calidad una obra, la crítica literaria, que juzga y valora la obra concreta, parece estar más apegada a la actualidad, al menos en lo que normalmente entendemos por crítica literaria. Canon y crítica tendrán que ver con largo periodo y corta distancia temporal, respectivamente.

Bien es verdad que desde muy antiguo ha existido esta práctica enjuiciadora de la obra concreta que llamamos crítica. Recuérdese el modelo antiguo de Aristófanes, cuya obra Las ranas (representada el año 405 a. C.), «was probably the earliest of all the masterpieces of hostile literary criticism, and which remains to this day among the very finest of them», en palabras de G. E. B. Saintsbury, en su monumental A History of Criticism and Literary Taste in Europe (1902-1904, I: 21) ${ }^{1}$. Tendríamos, pues, en Las ranas, un ejemplo de obra canónica de la crítica literaria. También desde antiguo se han planteado problemas teóricos en relación con el papel de la crítica a la hora de consagrar las obras literarias y el discutible valor del criterio temporal que prejuzga como bueno lo antiguo. Léase la epístola 1 del libro II de Horacio. Por supuesto, la historia de la crítica encontrará, sobre todo a partir del siglo XVIII, abundantes materiales para la construcción de un canon, directa o indirectamente presente como modelo en lo que hoy calificamos de crítica literaria. Modelos relacionados con la weltliteratur tampoco faltan incluso en la España del siglo XVIII. En la Historia de la crítica literaria en España, de Pedro Sainz Rodríguez (1989: 83), leemos que el valenciano de Oliva, Gregorio Mayans y Siscar (1699-1781):

era corresponsal de las Acta eruditorum que se publicaban en Leipzig, y allí comunicaba noticias de la vida literaria de España. Una de ellas fue el origen de su polémica con los redactores del Diario de los Literatos, que juzgaron que les habían menospreciado en los informes que había enviado acerca de esta publicación.

${ }^{1}$ Las ranas trata de la disputa en el otro mundo entre Esquilo y Eurípides (muerto el año 407 a. C.), aspirante al cetro de la tragedia. La crítica consiste en señalar los defectos del contrario. Triunfará Esquilo, y Sófocles queda el segundo, antes de Eurípides (Véase Alfonso Reyes, 1941: 149-150.) 
El hecho reseñado demuestra el interés por la información de lo que ocurre en la literatura en distintas lenguas, o lo polémico de los juicios y valoraciones expuestas. En el prólogo de su monumental Historia de la crítica moderna (1750-1950), René Wellek señala bien el valor de los modelos que la crítica actual puede encontrar en el pasado:

A mi juicio, la historia de la crítica, lejos de ser asunto de pura arqueología, debe servir para iluminar y hacer posible la interpretación de nuestra situación actual, como, a su vez, solo se hará comprensible a la luz de una teoría literaria moderna.

Y si empieza su narración en 1750 es porque piensa que:

hay doctrinas y conceptos surgidos en las postrimerías del siglo XVIII, en pugna unos con otros, que aun hoy conservan toda su validez: el naturalismo, la concepción del arte como expresión y comunicación emotivas, el punto de vista místico y simbólico de la poesía, etc. (Wellek, 1955-1992, I: 7).

Pero no voy a seguir el camino de la construcción de un canon de crítica literaria, al modo en que se construye un canon de modelos literarios. Es decir, no voy a ofrecer una lista de modelos de crítica literaria, sino que quiero enfocar la cuestión desde un ángulo diferente. Y tomo pie en el cuadro de las disciplinas literarias trazado por René Wellek (1949: 22), el clásico de la teoría literaria, cuando dice que:

la crítica literaria y la historia literaria intentan, una y otra, caracterizar la individualidad de una obra, de un autor, de una época o de una literatura nacional, pero esta caracterización sólo puede lograrse en términos universales sobre la base de una teoría literaria.

Y aquí es donde quiero situarme: en la universalidad de los métodos y conceptos que la teoría literaria del siglo xx proporciona a la crítica. En este sentido, sí hay un canon, un conjunto de ideas que la teoría literaria ha proporcionado a la crítica ${ }^{2}$.

De algunos de los trabajos esenciales de la teoría literaria del siglo xx y de su relevancia para la crítica literaria es de lo que quiero decir algo. Se tra-

${ }^{2}$ Desde el punto de vista teórico, la relación entre historia, teoría y crítica está bien asentada al menos desde Dilthey, cuando en su Introducción a las ciencias del espíritu (1883: 69) explicó que esta clase de ciencias se componen de tres clases de proposiciones: hechos (historia), teoremas (teoría) y juicios estimativos y normas (crítica). 
taría de responder a la supuesta pregunta de un crítico que quisiera saber qué teorías, de entre la enorme producción de siglo Xx, le pueden ser útiles en su labor de enjuiciamiento de la obra concreta. Seguramente muchas de las ideas sonarán como elementos de la koiné del pensamiento crítico de hoy. Se trata de comentar dónde se originan en la historia de la teoría literaria del siglo XX.

Una idea que hoy nos parece, por evidente, que forma parte del conjunto de las de sentido común es la que sostiene que la crítica literaria debe ser inmanente, es decir, debe centrarse en la obra, y, a partir de lo que es literario, emitir sus juicios y valoraciones, sean éstos de la clase que se quiera (por ejemplo: estéticos, sociológicos, históricos o psicológicos). La literariedad, lo que hace que una obra sea literaria, debe constituir el objetivo del análisis y el fundamento de la crítica. Y la literariedad se concreta en los procedimientos literarios (constituyentes fonéticos y léxicos, disposición de las palabras, construcciones semánticas, etc.), cuya función estética fundamental es presentar como nueva la percepción de la realidad, al desautomatizar la percepción de la forma. Una forma nueva, original, nos lleva a una visión nueva, original, de la realidad. El crítico literario debe, pues, identificar en toda obra la originalidad formal.

El formalismo ruso de principios del siglo XX es el creador de esta nueva concepción de la literatura, que, desde la exigencia de un inmanentismo crítico, reinstaló el interés por la forma en el centro de los estudios de la obra literaria.

Un texto de Roman Jakobson, publicado en Praga en 1921, La nueva poesía rusa, establece muy bien las diferencias entre las nuevas propuestas y los estudios literarios tradicionales, entonces dominantes en la crítica literaria:

Así, el objeto de la ciencia de la literatura no es la literatura sino la literariedad, es decir, lo que hace de una obra concreta una obra literaria. Sin embargo, hasta ahora, los historiadores de la literatura se parecían más bien a aquella policía que, proponiéndose arrestar a alguien, cogiera totalmente al azar todo lo que encontrara en la casa, así como las personas que pasaran por la calle. De la misma forma, los historiadores de la literatura se servían de todo: vida personal, psicología, política, filosofía. En lugar de una ciencia de la literatura, se creaba un conglomerado de investigaciones artesanales, como si se olvidara que estos objetos pertenecen a las ciencias correspondientes: la historia de la filosofía, la historia de la cultura, la psicología, etc., y que estas últimas pueden perfectamente utilizar los monumentos literarios como documentos defectuosos, de segundo orden. Si los estudios literarios 
quieren convertirse en ciencia, deben reconocer el procedimiento como su «personaje» único. Después la cuestión fundamental es la de la aplicación, la justificación del procedimiento (Jakobson, 1973: 15. Traducción nuestra).

Por eso, para Jakobson, la historia literaria desde hace tiempo no es más que pura charla amena (causerie): se pasa alegremente de un tema a otro, de las consideraciones líricas sobre el refinamiento de la forma a las anécdotas de la vida del artista; las evidencias psicológicas alternan con problemas del fondo filosófico de la obra o del medio social. Fácil y gratificante es hablar de la vida, de la época, a partir de las obras literarias. Y, por supuesto, nada de terminología precisa (Jakobson, 1973: 31) ${ }^{3}$.

La crítica será, pues, inmanente y basada en la forma. Hoy nos parece indiscutible que hay que hablar de la obra y que el crítico literario debe conocer los artificios propios de la obra de arte verbal.

El formalismo ruso, pues, tiene que ser una parte del canon de la crítica literaria actual. Porque, además, su manera de entender la literatura — bien a través de los desarrollos posteriores que se inspiran en él (Escuela de Praga, formalismo francés de los años sesenta, por ejemplo), bien por coincidencia con las preocupaciones presentes en otros movimientos (estilística, por ejemplo) - es la dominante en la teoría literaria hasta los años 70. Y si después otras inquietudes matizan el inmanentismo, no hay duda de que las posiciones formalistas tienen el carácter de clásicas, y, por tanto, son imprescindibles en la formación de los universales teóricos que deben informar la crítica literaria.

Un ejemplo sorprendente de la forma en que se establecen relaciones entre movimientos aparentemente distintos en origen, nos lo ofrecen los tempranos contactos de formalismo ruso y teoría literaria hispánica. Como puede comprobarse por los datos que damos a continuación, los testimonios son anteriores a la difusión del formalismo ruso en Francia, por ejemplo.

La principal vía es la obra del austriaco René Wellek, miembro activo del Círculo de Praga entre 1930 y 1935, emigrado a los Estados Unidos cuando Checoslovaquia fue invadida por los alemanes, quien no puede ignorar las ideas formalistas cuando escribe, junto con Austin Warren, una muy conocida Teoría literaria (1949). Los autores, en el prólogo a la primera edición, reconocen como modelo para su obra, entre otros, la Teoría de la literatura

3 En esta misma línea están las valoraciones negativas de la historia literaria tradicional por parte de Dámaso Alonso (2002) («libro de claros literatos», en vez de historia de las obras), o Roland Barthes (1963: 138), que la califica de crónica, sucesión de hombres solos, más que historia. 
de Tomachevski (Wellek y Warren, 1949: 11-12). Y basta consultar el índice onomástico de la obra para apreciar que no falta ninguno de los nombres de los formalistas más conocidos, salvo el de V. Propp, quizá por el carácter muy específico de su aportación, que se limita al cuento folclórico. La obra de Wellek y Warren se tradujo en 1953 al español con un prólogo de Dámaso Alonso.

Si Wellek y Warren ponían entre los modelos de su obra el manual de Tomachevski, Dámaso Alonso en el prólogo a la traducción española del trabajo de Wellek y Warren hablaba de «entrañable afinidad» con los autores. Porque estos dos críticos, seguía Dámaso Alonso:

no sólo tocaban en esta TEORIA LITERARIA una gran parte de los temas que más me habían preocupado a lo largo de muchos años, sino que los trataban desde un punto de vista bastante cercano al mío, tanto que yo podía asentir sin la menor violencia a las tesis fundamentales de la presente obra (Wellek y Warren, 1949: 7).

Quizá no extrañará entonces que Helmut Hatzfeld establezca en 1956 una relación entre estilística y formalismo ruso. Lo que sí llama la atención es que sea en fecha tan temprana como la indicada, y en un trabajo titulado precisamente Métodos de investigación estilística, publicado además en una revista española (Revista de Ideas Estéticas, XIV, 43-65). Por lo demás, no se trata de una mención de pasada, sino de la recensión, en dos páginas, con referencias bibliográficas, y con un epígrafe propio: El formalismo ruso e investigación de métodos.

Mucho más llamativa es la página en que el mexicano Alfonso Reyes se refiere a la nueva crítica rusa en un trabajo de 1940, Apuntes sobre la ciencia de la literatura, cuando habla de la estilística. Allí están los nombres de Brik, Eichenbaum, Vinogradov y Zirmunski (Reyes, 1986: 440).

Mención especial merece en este contexto la obra de Juan Ferraté, Teoría del poema (1957), recopilación de trabajos fechados entre 1951 y 1957, que demuestran una familiaridad sorprendente con las más modernas teorías literarias de raíz formalista y semiológica. Un botón de muestra nada más. Un teórico de la literatura actual no puede por menos de sentir un sobresalto al leer en el trabajo de 1953 sobre «Arbres, de Josep Carner» la palabra opacidad referida a la poesía:

Pues bien, la poesía es, después de todo, eso: la opacidad lúcida y transparente. [...] La capacidad de Carner para la representación es, desde la ata- 
laya de su soledad, única. Desde el silencio propio, el instrumento de que se sirve para ver y hacernos ver se despliega libre y autónomo, esto es, sin nada previo que lo explique, sin razones ocultas fuera del poema, ni razones o agudezas explícitas siquiera en el poema. El poema no se explica: se comprende, objeto frente a nosotros, en su objetividad irreductible (Ferraté, 1957: 95).

Pero el inmanentismo formalista no es un formalismo chato y reductor de la crítica a un mero ejercicio académico, casi escolar, de análisis retórico de un texto. Esto nos lo enseñan movimientos clásicos de la teoría literaria del siglo Xx: unos herederos del formalismo ruso - como lo es de forma directa el Círculo Lingüístico de Praga, y de forma indirecta el estructuralismo formalista francés de los años 60-; otros que, sin filiación directa con el formalismo ruso, preconizan una crítica inmanente y al mismo tiempo interpretativa, como dentro de la crítica idealista ilustra de forma nítida Leo Spitzer y su teoría del círculo filológico. Aclaremos de forma muy breve algo de esto.

El desarrollo del formalismo ruso en la Escuela de Praga, ya desde el año 1926, lleva a la constitución de la primera teoría semiológica de la literatura por obra de Jan Muka ovský. Sin duda es digna de ser considerada como canónica su propuesta de modelo de la obra literaria, dentro de una teoría general del arte como hecho semiológico. En la Escuela de Praga, la influencia del estructuralismo linguístico (F. De Saussure), la fenomenología (Husserl) y la tradición académica de la estética checa encauzarán el quehacer hasta cierto punto mecanicista de los formalistas rusos. Para Muka ovský, la obra de arte tiene un carácter de signo, no identificable con el estado de conciencia individual del autor, ni del receptor. La obra existe como objeto estético situado en la conciencia de toda una colectividad. El símbolo exterior de este objeto estético inmaterial es la obra-cosa sensible.

Toda obra de arte es un signo autónomo compuesto de:

1) una obra-cosa, que funciona como símbolo sensible creado por el autor;

2) un objeto estético, colocado en la conciencia colectiva, y que funciona como significación;

3) una relación con la cosa significada, es decir, una relación con el contexto total de los fenómenos sociales de un medio determinado (ciencia, filosofía, religión, política, economía...). 
La relación con la cosa significada mira a una existencia distinta (acontecimiento, persona, cosa, etc.), pero esta relación no tiene valor existencial, es decir, no se puede plantear la cuestión de su valor documental auténtico. En literatura, como nos advierten tantas veces en el cine, cualquier coincidencia con hechos y personas reales es siempre casual, aunque a veces parezca mentira tal casualidad.

La comunicación presentada por Jan Muka ovský en 1934 en el Octavo Congreso Internacional de Filosofía, celebrado en Praga, con el título de L'art comme fait sémiologique sistematiza estas ideas.

De la productividad de la semiología en la crítica nos ha ofrecido muy buenos ejemplos Roland Barthes. La idea de un segundo lenguaje, un sistema connotativo, cuyo significante es la lengua de comunicación o cualquier otro sistema de representación, se inspira en la lingüística glosemática de Hjelmslev y constituye un poderoso instrumento de análisis crítico de la ideología. Sigue siendo utilísima para el crítico literario la lectura de su obra de 1957, Mythologies, que recoge textos escritos y publicados en la prensa entre 1954 y 1956. Barthes trata de desmontar la ideología que subyace en las más variadas manifestaciones de la cultura de masas. El análisis se apoya en una concepción estructural, inspirada, según confiesa él mismo, en Saussure: las representaciones colectivas deben tratarse como sistemas de signos; el signo mítico, signo de un lenguaje segundo, quiere que se acepte como natural lo que no es más que ideología, connotación, es decir, significados ideológicos añadidos: la fotografía del soldado negro vestido con el uniforme francés en la portada de Paris-Match mirando a la bandera tricolor significa:

que Francia es un Imperio, que todos sus hijos, sin distinción de color, sirven fielmente bajo su bandera y que no hay mejor respuesta a los detractores de un supuesto colonialismo que el celo con que este negro sirve a sus pretendidos opresores (Barthes,1957: 201).

La ruptura que la nueva forma de entender la literatura supuso en el panorama crítico de los años 60 quedó bien escenificada en la polémica de Barthes con el especialista en Racine, Raymond Picard (Nouvelle critique ou nouvelle imposture, 1965), desencadenada por la publicación del libro del primero Sur Racine, 1963. La discusión fue más allá de la obra del clásico francés y alcanzó a los presupuestos de la nueva crítica en su totalidad. En el manifiesto que refleja las posiciones de la nueva crítica, Critique et vérité (1966), destacamos sobre todo el llamamiento a reconocer la capacidad 
simbólica de la literatura. Pues la obra, según lo atestiguan los hechos, tiene muchos sentidos. Históricamente se comprueba cómo cambia el sentido de una obra. Pero es que esta variedad está en la estructura misma de la obra, y en esto es en lo que es simbólica. El símbolo es constante, y lo que varía es la conciencia de la sociedad y los derechos que la sociedad le concede. La lengua simbólica, a la que pertenecen las obras literarias, es, por estructura, una lengua plural.

Esta disposición plural existe también en la lengua propiamente dicha, pues sabida es la cantidad de ambigüedades que se presentan en el uso linguiístico, si no hay un contexto que fije el sentido. De manera similar, cuando se lee una obra, se puede añadir la situación, el contexto propio, para reducir sus ambigüedades, pero esta situación, que cambia de un lector a otro, compone la obra, no la encuentra.

La obra literaria, al tener por estructura un sentido múltiple, da lugar a dos discursos diferentes: el de la ciencia de la literatura y el de la crítica literaria.

La ciencia de la literatura es un discurso general cuyo objeto es no un solo sentido, sino la misma pluralidad de sentidos de la obra.

La crítica literaria, por el contrario, es un discurso que asume, con sus riesgos, la intención de dar un sentido particular a la obra. De dos maneras se puede dar un sentido a la obra: por la lectura, que es una donación silenciosa e inmediata de sentido; y por la crítica, en que la donación de sentido está mediatizada por un lenguaje intermediario.

A continuación se detiene Barthes en un intento de caracterización de estos tres modos de acercamiento a la obra literaria. Por lo que se refiere a la ciencia de la literatura, ésta será una ciencia de las formas, interesada por las variaciones de sentido engendradas por la obra. Lo que le interesa saber es si la obra ha sido comprendida, y si todavía lo es, de acuerdo con la lógica simbólica de los hombres.

La crítica literaria no trata de los sentidos, sino que produce los sentidos; no busca el fondo de la obra, puesto que no existe, sino que sólo puede continuar las metáforas de la obra.

En lo que atañe a la lectura, señala Barthes la diferencia entre lectura y crítica, que se puede resumir diciendo que el lector desea la obra, mientras que el crítico desea el lenguaje de la obra. Lo que significa que la crítica quiere ser creadora, simbólica, como lo es el lenguaje literario. 
Terminemos destacando la importancia del concepto de texto plural y de la nítida distinción entre ciencia de la literatura, crítica y lectura ${ }^{4}$.

El ejemplo de lectura que dio Barthes en su análisis de la narración corta de Balzac, Sarrasine, en S / Z (1970), constituye ya un modelo clásico de manifestación del sentido plural de la obra. Y ha servido de ejemplo en los desarrollos postestructuralistas de la crítica americana.

Basten estos ejemplos para mostrar cómo la semiología ensancha el inmanentismo centrado en el significante del texto con una atención al significado, a lo que significa el texto.

En la semiología está también el germen del cambio más importante que va a experimentar la teoría literaria a partir, fundamentalmente, de los años 70, cuando las preocupaciones de la misma van más allá del texto. Irrumpe la consideración del receptor en la comprensión del fenómeno literario como hecho comunicativo en su conjunto, incluyendo también el texto. La estética de la recepción, la pragmática literaria y la deconstrucción son corrientes cuyas propuestas, preocupaciones y actividad se entienden en lo que hay que considerar ya como nuevo paradigma. Cambio nuevo no sólo en los estudios literarios sino en las humanidades en general.

Es la hermenéutica la filosofía guía ahora, lo mismo que con el estructuralismo era la lingüística la que proporcionaba los conceptos teóricos de las otras actividades humanísticas. Si hasta entonces es el Curso de Lingüística General (1916) de Ferdinand de Saussure la biblia, ahora es la obra de H.-G. Gadamer, Verdad y método. Fundamentos de una hermenéutica filosófica (1960), la que inspira los principios generales. En las cerca de 700 páginas que tiene la obra en su traducción española, el interesado encontrará las ideas esenciales de esa nueva koiné, lenguaje común, de las humanidades y la estética que es la hermenéutica hoy, según Vattimo (1991: 55). La cuestión de la verdad desde la experiencia del arte, con un apartado de especial significación sobre la ontología de la obra de arte y su significado hermenéutico; la expansión de la cuestión de la verdad a la comprensión en las ciencias del espíritu; y el lenguaje como hilo conductor del giro ontológico de la hermenéutica, tales son los grandes apartados, que nos dan idea del alcance estético, epistemológico y lingüístico de esta impresionante obra.

${ }^{4}$ Esta distinción de Barthes está próxima a la que Dámaso Alonso había hecho en Poesía española (1950) de tres clases de intuición: la del lector, la del crítico y la del estilista. En este momento hay que recomendar las páginas que en dicha obra dedicaba a la función de la crítica (Dámaso Alonso, 1971: 19216). 
Las seis páginas (Gadamer, 1960: 212-217) dedicadas a «La posición límite de la literatura» darían materia para el comentario de varios artículos. Reproducimos literalmente algunas de sus afirmaciones, referidas a la recepción de la obra, el canon y la literatura universal, para comprender la actualidad de sus planteamientos: «A la obra de arte literaria le pertenece la lectura de una manera esencial, tanto como la declamación o la ejecución». Pues la existencia de la literatura no es la permanencia muerta de un ser enajenado entregado a la realidad vivencial de una época posterior. Es decir, la literatura no es algo inerte, un objeto que está ahí, sino que «[...] la literatura es más bien una función de la conservación y de la transmisión espiritual, que aporta a cada presente la historia que se oculta en ella». E inmediatamente después la referencia a la formación de cánones, desde los filólogos alejandrinos, y su función en la creación de una tradición cultural viva que reconoce como patrón y transmite como modelo lo que conserva: la literatura clásica.

El desarrollo de la conciencia histórica desplaza la literatura universal de su pretensión normativa de unidad y la integra en el planteamiento histórico de la historia de la literatura, en un proceso inconcluso e inacabable. El concepto de literatura universal, sin embargo, sigue teniendo un sentido normativo «[...] ya que cuando atribuimos a una obra un significado realmente duradero decimos que forma parte de la literatura universal». Si toda la tradición linguística (textos religiosos, jurídicos, económicos, públicos y privados de toda clase, y los escritos que interpretan estos textos; es decir, todo el conjunto de las ciencias del espíritu) participa del modo de ser de la literatura es porque: «La capacidad de escritura que afecta a todo lo lingüístico representa el límite más amplio del sentido de la literatura» (Gadamer, 1960: 215).

En el fenómeno de la literatura se encuentra el punto en el que el arte y la ciencia se invaden el uno al otro. La escritura es lo más extraño y lo más estimulado de la comprensión:

La escritura, y la literatura en cuanto que participa de ella, es la comprensibilidad del espíritu más volcada a lo extraño. No hay nada que sea una huella tan pura del espíritu como la escritura, y nada está tan absolutamente referido al espíritu comprendedor como ella. En su desciframiento e interpretación ocurre un milagro: la transformación de algo extraño y muerto en un ser absolutamente familiar y coetáneo (Gadamer, 1960: 216).

Las reliquias materiales del pasado (edificios, instrumentos...) sufren la erosión del tiempo, sin embargo, 
La tradición escrita, desde el momento en que se descifra y se lee, es tan espíritu puro que nos habla como si fuera actual. Por eso la capacidad de lectura, que es la de entenderse con lo escrito, es como un arte secreto, como un hechizo que nos ata y nos suelta. En él parecen cancelados el espacio y el tiempo. El que sabe leer lo trasmitido por escrito atestigua y realiza la pura actualidad del pasado (Gadamer, 1960: 217).

En todo texto, la huella de sentido muerta se hace sentido vivo por la comprensión. La obra de arte literaria sólo se realiza del todo en su lectura. Aquí podríamos enlazar con una larga tradición de pensamiento sobre la producción continua de sentido en las lecturas de la obra. Baste recordar al monje Casiano (s. V) («nos hacemos, por así decir, autores de lo que leemos»), o San Gregorio Magno (s. VI) («la escritura crece con quien la lee»). Y se puede llegar hasta Ortega y Gasset o Jorge Luis Borges.

Este resumen apresurado de unas pocas páginas dedicadas a la literatura nos hará entender la fascinación sentida por corrientes como la estética de la recepción. En el manifiesto de dicha escuela, la lección pronunciada por Hans Robert Jauss, el 13 de abril de 1967 en la Universidad de Constanza, y traducido al español tan pronto como en 1971, La historia literaria como desafío a la ciencia literaria, es evidente la inspiración gadameriana del proyecto de renovación de los estudios literarios basada en una nueva visión de la historia literaria, donde la «[...] vida histórica de la obra literaria es inconcebible sin el papel activo que desempeña su destinatario» (Jauss, 1970: 68-69).

No quiero alargarme en más detalles de historia de la teoría literaria. Sólo me gustaría notar que si nos atenemos a la definición de la pragmática —una de las ramas de la semiótica, junto a la sintaxis y la semántica- como el tratamiento de las relaciones del signo con su intérprete, la estética de la recepción es una corriente que se integra en el movimiento general postestructuralista del desarrollo de tal rama de la semiótica.

Lo literario se ve hoy como un funcionamiento, registro, uso lingüístico marcado socialmente, más que como un conjunto de propiedades linguísticas o hechos de estilo exclusivos del fenómeno literario.

En este contexto de protagonismo del intérprete, de lo institucional y convencional, de la recepción de la obra, la crítica tiene un papel fundamental como factor determinante en gran medida de la transmisión y repercusión de los textos que van a ser literarios. Todas las grandes obras cuentan con comentarios excelentes. Un comentario excelente canoniza una obra (ejemplo: Dámaso Alonso canoniza a Góngora con su comentario). 
Además, el nuevo clima teórico induce a una nueva lectura de la teoría del pasado. Esta nueva lectura de la historia de la teoría destaca aspectos y obras que en otros momentos han podido pasar desapercibidos, o se han considerado de manera distinta.

Por ejemplo, hoy cobra nuevo interés en la teoría literaria una propuesta como la de Leo Spitzer sobre un método de lectura estrechamente vinculado a la hermenéutica. Para llegar a la unidad de la obra, objetivo de su análisis, conviene proceder desde la superficie hasta el centro vital interno de la obra de arte; observar primero los detalles en el aspecto superficial; agrupar los detalles, y tratar de integrarlos en un principio creador que hubiera podido estar presente en la obra del artista; tratar de explicar los otros detalles de acuerdo con el principio creador para ver si la «forma interna» explica todos los rasgos de la obra.

Leo Spitzer da nombre a su método: «Mi método de vaivén de algunos detalles externos al centro interno y, a la inversa, del centro a otras series de detalles, no es sino la aplicación del "círculo filológico"» (1955: 35). Este método se basa en un principio inductivo, y como operaciones previas exigidas por el mismo, sólo se le ocurre a Spitzer el dar el consejo de «leer y releer, paciente y confiadamente».

Por si hiciera falta, el mismo Spitzer, en una larga nota a este pasaje, explica la relación del círculo filológico con el círculo hermenéutico de Schleiermacher y con Heidegger. Y lo que más nos sorprende hoy, tiene que justificar esta relación con la hermenéutica y defenderse del prejuicio tradicional de la «viciosidad» de tal círculo.

Igualmente brilla de forma distinta la obra de José M. ${ }^{a}$ Castellet La hora del lector (1957), que leída hoy adquiere un significado profético casi. Sorprende, en efecto, la vigencia de afirmaciones publicadas diez años antes del famoso manifiesto de H. R. Jauss. Decía, por ejemplo, Castellet (1957: 11):

[...] esta obra quiere, ante todo, subrayar la importancia que el lector adquiere, en nuestros días, como activo creador de la obra de arte literaria. El lector es, pues, hoy nuestro tema y, para intentar ayudarle a tomar conciencia de su importancia en la literatura de nuestro tiempo, se han escrito estas páginas.

En el apartado titulado Aparición de la idea de la lectura como creación, junto a José Ortega y Gasset, se encuentra la mención de Roman Ingarden, cuya importancia para la estética de la recepción es conocida. En este mismo 
capítulo segundo, que lleva un título idéntico al de la obra, La hora del lector, destacamos la modernidad del paralelismo que establece entre la desaparición técnica del autor (otro tópico de la crítica moderna) y la importancia del lector. Por todo ello hay que saludar como muy oportuna la edición crítica que de la obra de José María Castellet ha hecho recientemente Laureano Bonet en Ediciones Península (2001).

Otro ejemplo. La obra de Mijail M. Bajtín (1895-1975) —a quien Todorov considera una de las figuras más fascinantes y enigmáticas de la cultura europea de la mitad del siglo XX- se difunde en occidente en los años 60 y 70 y todavía hoy es punto de referencia obligada para muchas cuestiones. Su pensamiento sobre el dialogismo puede ilustrar esta afirmación. El conjunto de enunciados constituye la vida verbal de una comunidad, que se caracteriza por una heterología, una diversidad de enunciados. La relación entre los enunciados es llamada por Julia Kristeva y por Todorov intertextualidad, y es lo que Bajtín llama dialogismo. Veamos, en palabras de Bajtín, cómo se caracteriza este fenómeno:

La orientación dialógica es, por supuesto, un fenómeno característico de todo discurso. Es la dirección natural de todo discurso vivo. El discurso encuentra el discurso de otro en todos los caminos que llevan hacia su objeto, y no puede dejar de entrar en interacción viva e intensa con él. Sólo el Adán mítico, abordando con el primer discurso un mundo virgen y aún no nombrado, el solitario Adán, podía verdaderamente evitar de manera absoluta esta reorientación mutua en relación al discurso de otro, que se produce en el camino hacia su objeto (Todorov, 1981: 98. Traducción nuestra).

La novela es el género que ha centrado la mayor parte de los análisis de Bajtín. Esto se explica por ser el género que precisamente mejor ilustra el concepto de dialogismo lingüístico. El funcionamiento del plurilingüismo, de la polifonía de voces presentes en el texto, del dialogismo, queda perfectamente descrito en la siguiente caracterización de la novela, que, como ejemplo, se reproduce en los mismos términos de Bajtín (1975: 87):

La novela, considerada como un todo, es un fenómeno pluriestilístico, plurilingüístico, plurivocal. El analista se encuentra en ella con ciertas unidades estilísticas heterogéneas, en planos lingüísticos diferentes y sometidas a diversas reglas estilísticas (Traducción nuestra).

En conclusión, lo que he querido manifestar es que la crítica literaria puede y debe aprovechar bastante de la teoría literaria del siglo Xx. Y que, de 
forma muy general, las lecciones que pueda aprender de esta teoría se refieren fundamentalmente a un inmanentismo, una preocupación por el sentido y una historización de la recepción del texto, lo que lleva a reconocer cierto relativismo e individualismo en el uso de la literatura. Es decir, formalismo, semiótica y hermenéutica son tendencias de la teoría literaria del siglo Xx que proporcionan conceptos muy útiles a la crítica literaria. Conceptos que como los de literariedad, connotación y expectativas del receptor deben figurar en la base de la labor crítica.

¿Puede proponerse un canon de teoría literaria utilizable en la crítica? Mi elección, breve y arriesgada como cualquier otra, comprendería los siguientes títulos:

1. Todorov, T. (ed.) (1965). Théorie de la littérature.

2. Muka ovský, J. (1934). L’art comme fait sémiologique.

3. Wellek, R.; Warren, A. (1949). Teoría literaria.

4. Alonso, D. (1950). Poesía española.

5. Spitzer, L. (1955). Lingüística e historia literaria.

6. Jakobson, R.; Lévi-Strauss, C. (1962). «Les Chats» de Charles Baudelaire.

7. Barthes, R. (1966). Critique et vérité.

8. Derrida, J. (1967). La structure, le signe et le jeu dans le discours des sciences humaines.

9. Jauss, H.-R. (1970). La historia literaria como desafío a la ciencia literaria.

10. Bajtín, M. M. (1975). Esthétique et théorie du roman.

\section{REFERENCIAS BIBLIOGRÁFICAS}

ALONSO, D. (1971). Poesía española. Madrid: Gredos, 5. a edición, reimpresión.

- (2002). «Para un proyecto de historia de la literatura», edición de José Polo. Analecta Malacitana XXV.1, 277-285.

BAJTÍN, M. M. (1975). Esthétique et théorie du roman, trad. de Daria Olivier. París: Gallimard, 1978 [Hay traducción española: Madrid: Taurus, 1989]. 
BARTHES, R. (1957). Mythologies. París: Seuil, 1970.

— (1963). Sur Racine. París: Seuil.

- (1966). Critique et vérité. París: Seuil.

- (1970). S / Z. París: Seuil.

CASTELlET, J. M. ${ }^{a}$ (1957). La hora del lector. Barcelona: Seix-Barral. (Edición crítica al cuidado de Laureano Bonet. Barcelona: Península, 2001.)

DERRIDA, J. (1967). La structure, le signe et le jeu dans le discours des sciences humaines. En L'écriture et la différence, 409-418. París: Seuil.

DILTHEY, W. (1883). Introducción a las ciencias del espíritu, versión española de Julián Marías, prólogo de José Ortega y Gasset. Madrid: Alianza Editorial, 1986.

DOMÍNGUEZ CAPARRÓS, J. (2002). Teoría de la literatura. Madrid: Centro de Estudios Ramón Areces, 2004, primera reimpresión.

FERRATÉ, J. (1957). Teoría del poema. Barcelona: Seix-Barral.

GADAMER, H.-G. (1960). Verdad y método, traducción de Ana Agud Aparicio y Rafael de Agapito. Salamanca: Sígueme, 1984.

HATZFELD, H. (1956). «Métodos de investigación estilística». Revista de Ideas Estéticas XIV, 43-65.

JAKOBSON, R. (1973). Questions de poétique. París: Seuil.

JAKOBSON, R.; LÉVI-STRAUSS, C. (1962). «Les Chats» de Charles Baudelaire, traducción de Celia Amorós. En J. Vidal Beneyto, Posibilidades y límites del análisis estructural, 143-160. Madrid: Editora Nacional, 1981.

JAUSS, H.-R. (1970). «La historia literaria como desafío a la ciencia literaria». En Gumbrecht, H.-U. y otros, La actual ciencia literaria alemana, traducción de H.-U. Gumbrecht y Gustavo Domínguez León, 113-221. Salamanca: Anaya, 1971.

MUKA OVSKÝ, J. (1934). «L'art comme fait sémiologique». Poétique 3, 1970, 387-392.

PICARD, R. (1965). Nouvelle critique ou nouvelle imposture. París: J.-J. Pauvert. 
REYES, A. (1941). La crítica en la edad ateniense. En Obras Completas, vol. XIII. México: FCE, 1983, 1. a reimpresión.

— (1986). La experiencia literaria. Barcelona: Bruguera.

SAINTSBURY, G. E. B. (1902-1904). A History of Criticism. Genève: Slatkine, 1971, 3 vols.

SAINZ RODRÍGUEZ, P. (1989). Historia de la crítica literaria en España. Madrid: Taurus.

SPITZER, L. (1955). Lingüística e historia literaria. Madrid: Gredos, 1974, 2. ${ }^{a}$ edición.

TODOROV, T. (ed.) (1965). Théorie de la littérature, textes des formalistes russes. París: Seuil.

— (1981). Mikhail Bakhtine. Le principe dialogique. París: Seuil.

VATTIMO, G. (1991). Ética de la interpretación, trad. Teresa Oñate. Barcelona: Paidós.

WELLEK, R. (1955-1992). Historia de la crítica moderna (1750-1950), varios traductores. Madrid: Gredos, 1969-1996, 7 vols.

WELLEK, R.; WARREN, A. (1949). Teoría literaria, versión española de José M. ${ }^{a}$ Gimeno. Madrid: Gredos, 1969, 4. ${ }^{a}$ edición. 